\title{
Citation Counts and Social Comparisons: Scientists' Use and Evaluation of Citation Index Data
}

\author{
Lowell L. Hargens \\ University of Illinois \\ AND \\ Howard SChuman \\ University of Michigan
}

\begin{abstract}
Data from samples of biochemists and sociologists show that nearly all are familiar with citation indexes and that the two groups are equally likely to have used a citation index for bibliographic purposes. We develop three hypotheses from social comparison theory to account for variation in use and evaluation of citation counts as indicators of scientific achievement: (1) more highly cited scientists will more often use and more highly evaluate citation counts as indicators of scientific achievement than will less cited scientists, (2) these relationships will be stronger for sociologists than for biochemists. and (3) sociologists as a whole will more often use and more highly evaluate citation counts than biochemists. Finally, among sociologists, we hypothesize that those primarily interested in quantitative research areas will use and favor citation counts more than those with primarily qualitative or theoretical interests. Our data support all but one of these hypotheses. We also report unexpected differences in use and evaluation of citation counts by sex and departmental prestige. 1990 Academic Press, Inc.
\end{abstract}

Academic scientists are ambivalent about attempts to measure scholarly contributions. They often view such attempts negatively because they fear that using quantifiable characteristics to guage contributions leads to the distortion of research products. For example, widespread use of publication counts as a basis for promotion decisions is sometimes blamed for a deluge of trivial publications. Scientists see their research as craft work (Whitley, 1984:6-7), and many believe that using one or

Send correspondence to Lowell Hargens, Department of Sociology, University of Illinois, Urbana, IL 61801. The authors shared equally in this research. Our work profited from the suggestions of Laura Klem and Barbara Reskin. 
two easily quantifiable aspects to assess a scientist's scholarly product tends to debase that product. ${ }^{1}$

Yet assessing scholarly contributions quantitatively has undeniable attractions as well. Decisions about tenure, promotion, and other academic awards are necessary, and quantitative information about performance ordinarily plays a role in them (Braxton and Bayer, 1986). Furthermore, reliance on quantitative measures may protect evaluators from charges that their decisions are particularistic, or are based on candidates' ascriptive characteristics (Lewis, 1975:40-42). Finally, academic research work is a nonroutine, often ambiguous activity with infrequent formal assessments of one's performance. Individuals in such circumstances are likely to seek evidence about their relative performance (Festinger, 1954), and quantitative forms of evidence may be especially attractive because they appear to be "objective."

Since its initial publication in 1964 by the Institute of Scientific Information, the Science Citation Index (SCI) has made it relatively easy to count how often an individual has been cited by other scholars during a given year. Although the SCI was developed as a bibliographic tool to help scientists trace the literature in their areas of interest (Garfield, 1979:49-61), measuring the impact of individuals' work has become the SCI's most visible and controversial use (Wade, 1975; Garfield, 1979:240252). The controversy about such use bears witness to scientists' ambivalence toward citation counts as measures of scholarly performance.

In this paper, we report results from a survey of academic scientists' use and evaluation of citation count information. In part, we sought to determine if patterns of use and evaluation are consistent with Festinger's (1954) social comparison theory, especially as integrated with attribution theory (Goethals and Darley, 1977). Festinger hypothesized that people desire to evaluate their own abilities, and that when they lack objective measures, they resort to comparing themselves to others. Goethals and Darley added that people want to find that their abilities-necessarily measured in terms of performance-compare favorably with others'. We developed three hypotheses about scientists' use and evaluation of citation counts from social comparison theory. The first and most general hypothesis is

1. Scientists who are highly cited will be more likely to use citation counts for gauging scholarly contributions than will infrequently cited scientists. The former will also evaluate citation counts for this purpose more highly than the latter

We assume that most scientists feel that their own research contributions

\footnotetext{
' Stigler (1984) makes this point forcefully in his satire "An Academic Episode" in which an academic administrator radically changes faculty members' behavior by setting up and altering a system for measuring scholarly merit.
} 
are important, but that they also seek support for these self-evaluations. Discovering that one's work is highly cited confirms positive self-evaluations and at the same time validates citation counts as a measure of scholarly contribution. This is a kind of construct validation in which both constructs-the merit of one's work and the value of citation counts-support each other. In contrast, infrequently cited researchers should be less likely to regard citation counts a valid measure of scholarly contributions because citation counts do not support their tendency to evaluate their own work positively.

We tested this hypothesis by drawing samples of scientists at U.S. universities in two quite different fields: biochemistry and sociology. We selected these fields in part because of the avilability of sampling frames that gave university affiliations and other relevant information. We expected the relationship stated in hypothesis 1 to apply in each field, but on the basis of evidence that the natural sciences exhibit a higher level of consensus than the social sciences, ${ }^{2}$ we also expected certain differences between them. Specifically, studies of the social organization of research work (Lodahl and Gordon, 1972; Hargens, 1975), the evaluation of scholars (Yoels, 1974; Hargens and Hagstrom, 1982), competition for priority in reporting research findings as indexed by both the incidence of being anticipated before publication and publication in the form of articles rather than books (Hagstrom, 1965), and the evaluation of research proposals (Cole and Cole, 1981) and papers submitted to journals (Zuckerman and Merton, 1972; Pfeffer, Leong, and Strell, 1977) all show higher levels of consensus in the natural than the social sciences. Evidence also suggests that differences in overall levels of consensus affect scholars' attributional patterns; Rubin (1975) found that chemists who had been denied tenure at Ph.D.-granting departments were more likely to blame themselves for their failure than sociologists, who more often disputed the validity of the criteria by which they were judged. These considerations led to two more hypotheses:

2a. Scientists in fields with relatively low levels of consensus on appropriate research questions and techniques are more likely to use citation counts to measure individuals' scholarly contributions than scientists in fields with relatively high levels of consensus. The former will also evaluate such use of citation counts more favorably than the latter.

This relationship derives from Hypothesis II of Festinger's (1954) statement of social comparison theory: when more objective means of evaluation are unavailable, people evaluate themselves by comparison with

2 A number of concepts roughly correspond to our "level of consensus," including "paradigm status" (Lodahl and Gordon, 1972), "degree of codification" (Zuckerman and Merton, 1972), and the "hard-soft" dimension (Biglan, 1973; Smart and Elton, 1982). 
others. In this case, lack of consensus about the importance of contributions in a field should lead its members to be less certain about the value of their own and others' research contributions than in fields with high levels of consensus, and this should lead them to seek means of gauging contributions more than members of high-consensus fields. ${ }^{3}$ Furthermore

$2 b$. The relationship between one's own citation level and one's use of citation counts to measure scholarly contributions will be stronger in fields with less consensus than in fields with more consensus. Similarly, the relation between one's own citation level and one's evaluation of citation counts as a measure of scholarly contributions will be greater in low- than in high-consensus fields.

The predictions in hypothesis $2 \mathrm{~b}$ follow from those in hypotheses 1 and 2a. Highly cited biochemists should feel less need to use citation counts for evaluation since at best they would be redundant with widely shared evaluations among others in the field. As a result, the validation citation counts afford to those whose work is highly cited should be less in biochemistry than in sociology. Moreover, infrequently cited sociologists should be more negative toward citation counts than infrequently cited biochemists because the former are more likely to be able to argue that the citation-count "evidence" is inconsistent with other evaluations of their work. Indeed, in sociology having one's work infrequently cited is sometimes viewed as a sign that one rejects current research fads and instead concentrates on more important, although unfashionable, projects.

We also developed an hypothesis that is unrelated to social comparison theory but which stems from scientists', perhaps especially social scientists, skepticism about trying to measure scholarly contributions. Sociologists often disagree about whether quantitative data can contribute significantly to understanding social behavior. Therefore, we reasoned that those who doubt the value of quantitative data generally should have a low opinion of citation counts quite apart from other factors. Thus, even if sociologists are more positive toward citation counts than biochemists as a result of social comparison processes, the fact that a subset of sociologists denigrate any form of quantitative evidence could obscure the field differences.

Each of the above hypotheses specifies a relationship that should hold independently of other possible causes of scientists' use and evaluation of citation counts. To evaluate the accuracy of the predictions, an anal-

"Hargens and Hagstrom (1982) studied the link between consensus and the ability to gauge research potential and past contributions, and found results consistent with their predictions about how status-attainment patterns should vary across fields with differing levels of consensus. 
ysis must, insofar as possible, include other causes that may be correlated with the independent variables at issue. Thus, we gathered data on other variables that might affect the use and evaluation of citation counts beyond the effects discussed above.

\section{SAMPLING AND DATA COLLECTION}

We sampled from the lists of biochemistry graduate faculty in the American Chemical Society's Directory of Graduate Research (1984) and sociology graduate faculty in the American Sociological Association's Guide to Graduate Departments in Sociology (1985). We decided to draw the samples from high- and low-prestige departments, as measured by departments' reputational rankings reported by Jones, Lindsey, and Coggeshall (1982), because the reputational rankings of departments are substantially associated with measures of the eminence of their members (Cole and Cole, 1973; Long, 1978).

We sought responses from at least 50 associate and full professors in each discipline-prestige combination, and expected a response rate of about $75 \%$ given the brevity of our questionnaire, which we designed to fit on a postcard (our questionnaire is reproduced in the Appendix). In addition, we wanted to include no more than one-third of the members of any one department in our sample. Accordingly, we began by determining the number of high prestige biochemistry departments required to produce a sampling frame of at least 200 persons, the number of low prestige biochemistry departments which met the same condition, etc. ${ }^{4}$ Next, we determined the sampling fraction for each group that would yield a sample of approximately 66 members. We then randomly selected the four samples and mailed explanatory letters plus questionnaires in late April 1985. Three weeks later we mailed follow up questionnaires to nonrespondents. Table 1 gives, for each of the four groups, the range of prestige scores of the departments, the number of associate and full professors, the numbers we selected for our samples, the numbers who returned questionnaires, and the return rates. ${ }^{5}$

In addition to questionnaire data, we collected biographical data on the members of our samples. We obtained information on their sex, academic rank, and year of Ph.D. (or M.D. for a few biochemists) from

${ }^{4}$ We needed at least 200 members in each of the four groups because (1/3) (3/4) 200 $=50$. We excluded from our sampling frame persons with ranks below associate professor because their typically low citation levels only reflect their professional youth. We also omitted professors emeriti.

${ }^{5}$ Table 1 shows that members of highly ranked departments were less likely to return questionnaires than members of low ranked departments. In addition, within each field citations to sample members' work was negatively correlated with whether they responded: for biochemistry $r=-.17$ and for sociology $r=-.18$. Thus, eminent scholars are slightly underrepresented in our samples. 
TABLE 1

Characteristics of the Sample Strata and Response Rates, by Discipline and Department Prestige Level

\begin{tabular}{lccccc}
\hline $\begin{array}{l}\text { Discipline- } \\
\text { prestige } \\
\text { combination }\end{array}$ & $\begin{array}{c}\text { Range } \\
\text { of } \\
\text { prestige } \\
\text { scores }^{u}\end{array}$ & $\begin{array}{c}\text { No. of } \\
\text { Associate and } \\
\text { Full Professors }\end{array}$ & $\begin{array}{c}\text { No. } \\
\text { Sampled }\end{array}$ & $\begin{array}{c}\text { No. } \\
\text { Responded }\end{array}$ & $\begin{array}{c}\text { Response } \\
\text { Rate }\end{array}$ \\
\hline $\begin{array}{c}\text { Biochemistry } \\
\text { High prestige }\end{array}$ & $74-65$ & 234 & 66 & 46 & $70 \%$ \\
$\begin{array}{c}\text { Biochemistry } \\
\text { Low prestige }\end{array}$ & $45-33$ & 200 & 67 & 52 & $78 \%$ \\
$\begin{array}{c}\text { Sociology } \\
\text { High prestige }\end{array}$ & $71-63$ & 195 & 64 & 49 & $77 \%$ \\
$\begin{array}{c}\text { Sociology } \\
\text { Low prestige }\end{array}$ & $43-28$ & 209 & 69 & 57 & $83 \%$ \\
\hline
\end{tabular}

Source: Jones et al. (1982).

the directories we sampled from. For a few sample members for whom the directories did not include these data, we used the most recent edition of American Men and Women of Science. We also collected bibliometric data, including each sample member's number of citations in the 1984 SCI or Social Science Citation Index (SSCI), and the median number of citations for all of the associate and full professors in each sample member's department. We collected data on the latter variable to assess the possibility that researchers' perceptions of their relative eminence are based on their relative standing among the members of their own departments as well as on their relative standing among all the members of their disciplines. After gathering these and other data, we worked only with identification numbers to protect our respondents' confidentiality.

Finally, for our sociology sample we constructed a measure of whether a respondent is likely to view the quantitative analysis of empirical data favorably by using information about the specialties they listed in the 1985 Guide to Graduate Departments in Sociology. ${ }^{6}$ Our measure class-

\footnotetext{
'We began by listing specialities whose members are, in our experience, typically either favorably or unfavorably disposed toward using quantitative data. Our list of quantitatively oriented specialties included "quantitative methods," "statistics," "research methods," "evaluation research," "demography," and "population." Our list of nonquantitatively oriented specialities included "theory." "interpretive sociology," "comparative and historical sociology," "macro sociology," "religion," "culture," "cultural change," "field methods," "psychoanalytic sociology," "Marxist sociology," and "mathematical theory and modeling" (members of this last specialty often emphasize the importance of formal models for analyzing social phenomena and express skepticism about the value of statistical analyses of empirical data). We classified specialities not included in either of these two lists as "mixed." Next, we examined each sample member's list of specialites. We classified
} 
ified $34 \%$ of the sociologists in our sample as quantitatively oriented, $46 \%$ as mixed, and $20 \%$ as nonquantitatively oriented. ${ }^{7}$

\section{RESULTS}

Respondents in both fields were almost universally familiar with citation indexes, and approximately two-thirds in each had consulted them at some time. As Table 2 shows, about half of the respondents in each field reported that they had used citation indexes to locate recent publications-the purpose for which citation indexes were originally designed. Thus, field differences in familiarity and use of citation indexes to identify publications are small and none was statistically significant. The fourth item shows that, consistent with hypothesis $2 \mathrm{a}$, sociologists were more likely than biochemists to have used citation indexes to count how often particular individuals had been cited. Similarly, the fifth item shows that, on average, sociologists were more likely to favor using citation counts to measure scholarly contributions. Thus, the overall patterns of use and evaluation of SCI/SSCI shown in Table 2 are consistent with hypothesis $2 \mathrm{a}$.

In addition to the results for individuals, Table 2 shows data on departmental use of citation counts for making personnel decisions. We asked our respondents whether their departments had ever used citation counts in making decisions about salaries, hiring, and promotion. Although our study was not designed to gather highly reliable measures of departmental use of citation counts, the percentage of sociology departments in which at least one member reported that citation counts had been used for such purposes significantly exceeded that of biochemistry departments (see line 6 of Table 2). ${ }^{8}$ Thus, the results for departments are consistent with those for individuals (see line 4)-in both cases sociology showed higher use of citation counts than biochemistry.

sample members as quantitatively oriented if they listed only quantitative or both quantitative and mixed specialties. We classified sample members as nonquantitatively oriented if they listed only nonquantitative or nonquantitative and mixed specialties. We classified as mixed sample members with all other combinations. Note that since sociologists typically listed three or four specialties in their entries in the Guide to Graduate Departments in Sociology, the validity of our classification of individuals is probably greater than that of our classification of specialties.

We each classified the sociologists in our sample independently and obtained discrepant classificatons for only 13 of the 133 sociologists (and resolved the discrepancies on a caseby-case basis). The association between our independent classifications, when we treat the three categories as an ordinal measure of orientations toward quantitative data, yielded a $\gamma$ coefficeint of .997.

${ }^{8}$ We believe that our choice of at least one member reporting use of SCI or SSCI is appropriate because not all members of a department may be aware of such use. Using different numbers who report that their department has ever used citation counts for a cutoff. or using a certain proportion. yields different percentages than those reported in Table 2, but does not alter the disciplinary difference it shows. 
TABLE 2

Familiarity with and Use of SCI/SSCI, and Evaluation of Citation Counts for Evaluating Scholars, by Field

\begin{tabular}{lccr}
\hline Item & Biochemists & Sociologists & t-value \\
\hline 1. Familiar with SCI/SSCI & $97 \%$ & $93 \%$ & 1.17 \\
& $(98)$ & $(106)$ & .83 \\
2. Ever consulted SCI/SSCI & $65 \%$ & $71 \%$ & .29 \\
& $(95)$ & $(99)$ & \\
3. Used SCI/SSCI to locate recent work on a & $52 \%$ & $50 \%$ & \\
topic by examining citations to earlier papers & $(98)$ & $(106)$ & \\
$\quad$ on that topic & $39 \%$ & $51 \%$ & -1.75 \\
4. Used SCI/SSCI to determine how frequently & $(98)$ & $(106)$ & -2.90 \\
particular individuals have been cited & 4.41 & 5.40 & \\
5. Mean evaluation of citation counts as a way & $(91)$ & $(96)$ & \\
to evaluate individual scholars' contributions & & & \\
$\quad$ (l = not useful, 10 extremely useful) & $35 \%$ & $60 \%$ & $\chi^{2}$ \\
6. Percentage of departments that have ever & $(34)$ & $(30)$ & 3.91 \\
$\quad \begin{array}{l}\text { used citation counts in decisions about hir- } \\
\text { ing. promotions, or salaries }\end{array}$ & & & $(1 \mathrm{df})$ \\
\hline
\end{tabular}

The results in Table 2 showing the overall levels of use and evaluation of SCI/SSCI in the two fields provide a first test of hypothesis 2a. To further test $2 a$ and also hypotheses 1 and $2 b$, we carried out multivariate analyses of the two dependent variables that those hypotheses specified: use of citation indexes to count citations to particular individuals and evaluation of citation counts as a measure of scholarly contributions. In addition to the three independent variables that those hypotheses specified-researcher's own citation count, field, and the interaction of field and citation count-other variables are likely to affect the two dependent variables. For example, for sociologists we included positive/negative orientation toward quantitative data to test our final hypothesis. In addition, we examined other potential independent variables for which we had data to learn if they appreciably affected our dependent variables. Two such variables-respondent's sex and the average citation count in a respondent's department-did.

We measured field and sex with dummy variables whose reference categories (coded zero) are respectively biochemists and males. Because biochemists receive considerably more citations than sociologists do, to avoid conflating effects of field and citation counts we measured the degree to which our respondents' work is cited with field-specific standard scores rather than with raw citation counts (see Hargens, 1976). Our measure of the average citation count for a respondent's department, a contextual variable, is the field-specific standard score of the median number of citations to the associate and full professors in the department. We used field-specific standard scores here too to control for field dif- 
ferences in citations. We chose the median to measure central tendency because citation counts within departments, as in entire fields, are highly positively skewed. To measure sociologists' orientations to quantitative data, we assigned those we categorized as qualitatively oriented a score of zero, those we categorized as mixed a score of 1.0 , and those we categorized as quantitatively oriented a score of 2.0. Because only sociologists have scores on this variable, we made it independent of field by assigning all the biochemists the mean score for the sociologists (see Cohen, 1968 for a discussion of this method for handling missing data). Finally, in order to test our third hypothesis, we created a field-bycitations interaction term by multiplying these two variables.

Table 3 presents the results of regressing our two dependent variables, (a) whether one has consulted a citation index to count a particular individual's citations and (b) one's evaluation of citation counts as a measure of scholarly contributions, on the six independent variables discussed above. Because the first of these dependent variables is dichotomous, the assumptions of OLS analysis are not met (Hanushek and Jackson, 1977:179-186), so we carried out a logistic regression analysis. Thus, the results in the first column show the effects of each independent variable on the logit of the estimated probability that a respondent has consulted a citation index to count an individual's citations.

The coefficients in the first three rows and the first two columns in Table 3 bear on hypotheses 1, 2a, and $2 \mathrm{~b}$ as those hypotheses pertain to having used a citation index to count individuals' citations. Specifically, the coefficient for the field-specific standardized individual citation counts $(.18$, n.s.) represents its slope for biochemists. The coefficient for "field" $(.64, p<.05)$ represents the difference between the two regression lines for biochemists and sociologists who score at the mean of their respective field's citation distributions (i.e., those whose fieldspecific standardized citation counts equal zero). The coefficient for the interaction term represents the difference between the slopes for biochemists' and sociologists' citation counts (see Hanushek and Jackson, 1977: 106-108).

Our first hypothesis, that the number of citations a researcher receives should be positively related to using citation indexes to count citations, is only weakly supported by the data for biochemists because the coefficient in the left column of line 1 in Table 3, although positive, is not statistically significant. The first hypothesis clearly holds for sociologists, however (line 3), and it is also clear that the relation between one's own citation count and use of citation indexes is significantly stronger among sociologists than among biochemists. Finally, line 2 shows that sociologists who received the mean number of citations for their field are more likely to have counted citations than biochemists who received the mean number of citations for their field. In order to show the results for the 


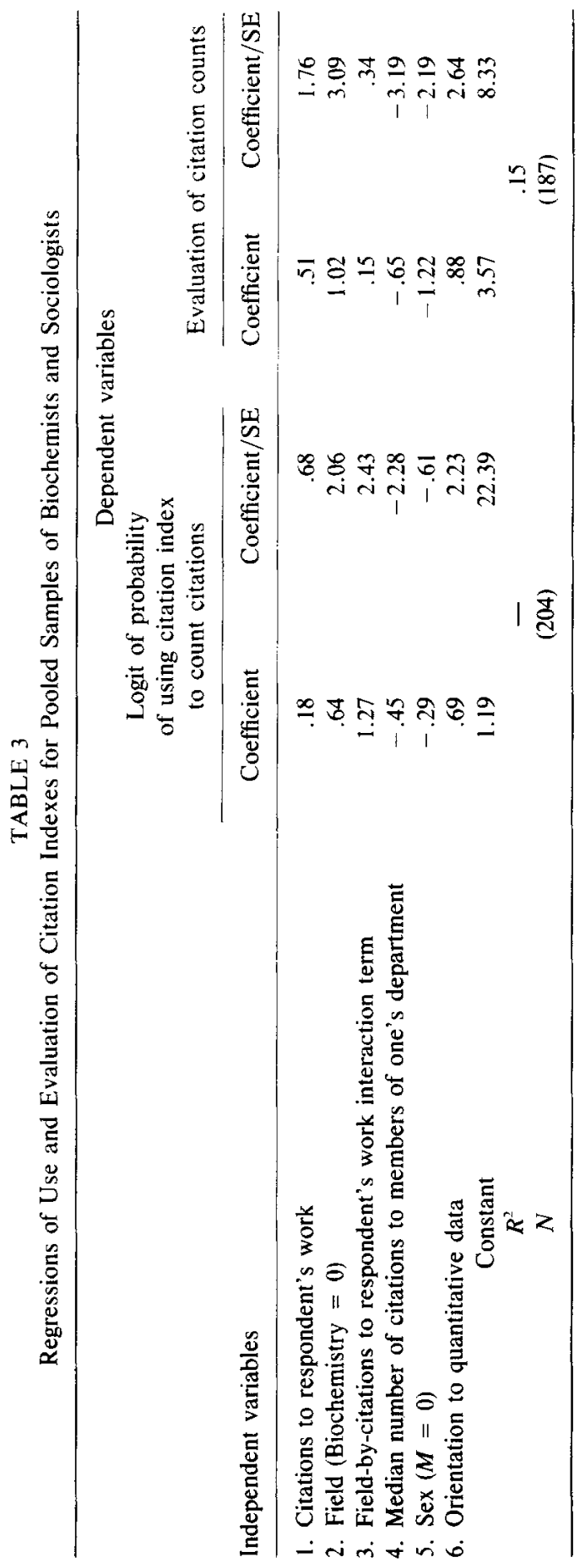




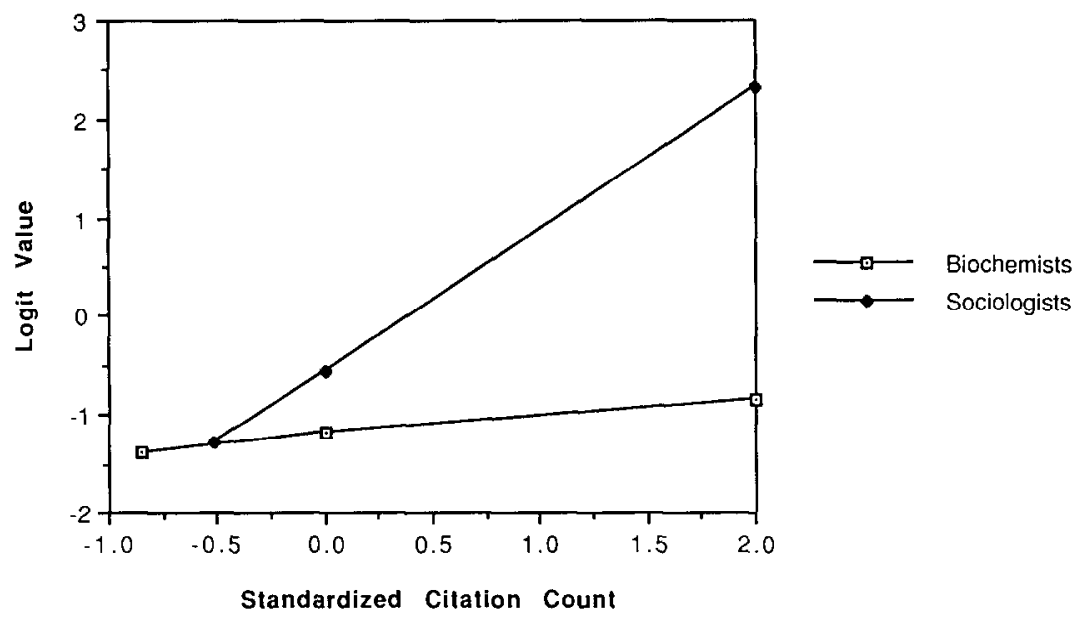

FIG. 1. Relation between Citations to One's Own Work and Logit Values for Using a Citation Index to Count Individuals' Citations, by Field.

complete range of citation counts for the two fields, Fig. 1 presents the field-specific regression lines for cases with values of zero on the other three independent variables. ${ }^{9}$ The results in Fig. 1 show that except for researchers with low standardized citation counts (who show no disciplinary difference in counting citations), sociologists are more likely to have done so than biochemists. Thus, the results in the two leftmost columns of Table 3 are consistent with the three hypotheses, except that the effect of one's citation count on the probability of having used a citation index to count citations is not statistically significant for biochemists. $^{10}$

The results in the first three rows and last two columns in Table 3 address the extent to which the data support the three hypotheses regarding respondents' evaluations of citations as information about individuals' scholarly contributions. These results indicate that (1) the

${ }^{y}$ We chose values of zero for convenience: the pattern of results would be the same for any other combination of values for the other independent variables, although the values of the logit represented on the $y$-axis of the graph would vary if we chose different values. Note that Fig. 1 does not cover the entire range of the positive values of the independent variable since the results for higher values are just extensions of the two regression lines. Also, the two regression lines have left-hand endpoints corresponding to the field-specific standard scores for those who received no citations-for biochemists this lowest possible score equals -.85 and for sociologists, -.52 .

${ }^{10}$ We explored whether additional interaction terms besides the field-by-citations received variable significantly improved our ability to predict counting citations by testing whether the set of all possible two-variable interaction terms significantly increased the coefficient of determination. Doing this increased that coefficient from .10 to .14 , a nonsignificant increment ( $F$ equals 1.10 with 8 and $189 \mathrm{df}$ ). 
number of citations both biochemists and sociologists receive are significantly positively related to their evaluations of citation indexes, (2) sociologists evaluate citation counts more highly than biochemists with equivalent standardized citation counts, and (3) the relationship between citations to one's work and evaluations of citation counts is not stronger among sociologists than among biochemists. Figure 2 presents these results graphically and shows that even among those who receive relatively few citations, sociologists evaluate citation indexes more highly than biochemists. The interaction term in this equation is not significant, so we also estimated an equation that omits it. The coefficients in the latter completely additive model were all within .02 of the coefficients reported in Table 3, except for citations to own work, which increased from .51 to .55 and became 2.2 times its standard error.

Thus, the results shown in Table 3 are consistent with hypotheses 1 and $2 \mathrm{a}$, but only partly consistent with hypothesis $2 \mathrm{~b}$. We are unable to conclusively explain this exception, especially as the two dependent variables-counting citations and evaluations of citation indexes-are moderately positively correlated (for the two fields combined $r=.48$; for biochemists and sociologists separately, .48 and .44 , respectively). ${ }^{11}$

In addition to the results pertinent to hypotheses $1,2 \mathrm{a}$, and $2 \mathrm{~b}$, Table 3 shows the effects of three other variables on our two dependent variables. The most noteworthy are those for the average citation level of one's department, whose effect can be interpreted as a contextual effect (Alwin, 1976). ${ }^{12}$ Its significant negative effects in Table 3 indicate that respondents from departments whose members tend to be highly cited

"Adding all possible two-variable interaction terms to the equation increased the coefficient of determination from .15 to $.20(F=1.38$ with 8 and $172 d f)$. Although one would normally conclude from this result that there is no substantial evidence that these interactions exist, one of the interactions in the set, field-by-median citations to the members of one's department, appears to differ significantly from zero $(t=2.48$ with $172 d f)$. The term shows that the relationship between evaluations of citation counts and departmental citations is weaker in sociology than in biochemistry (for sociology alone it still has a negative sign, but does not differ significantly from zero). When we added this term to the equation in Table 3, the coefficients for existing variables changed little and had $t$ values of at least $|2.0|$. except for the field-by-citations received interaction, which became negative but remained nonsignificant. We also note that when one analyzes the two fields separately, the slope for citations received is smaller in sociology than in biochemistry. Given the robustness of the findings for the "main effects" in Table 3 across alternate specifications of our model, and the consistent lack of significance for the hypothesized interaction term, we believe that our third hypothesis is not supported even though the sign for the interaction term shown in Table 3 is positive.

12 Specifically, Alwin showed that when one includes both individuals' scores on a variable and organizational means for that variable in a regression model, the coefficient for the latter measures the difference between individual-level and organizational-level slopes for that variable. As noted above. however, in our study we used organiazational medians rather than means. 


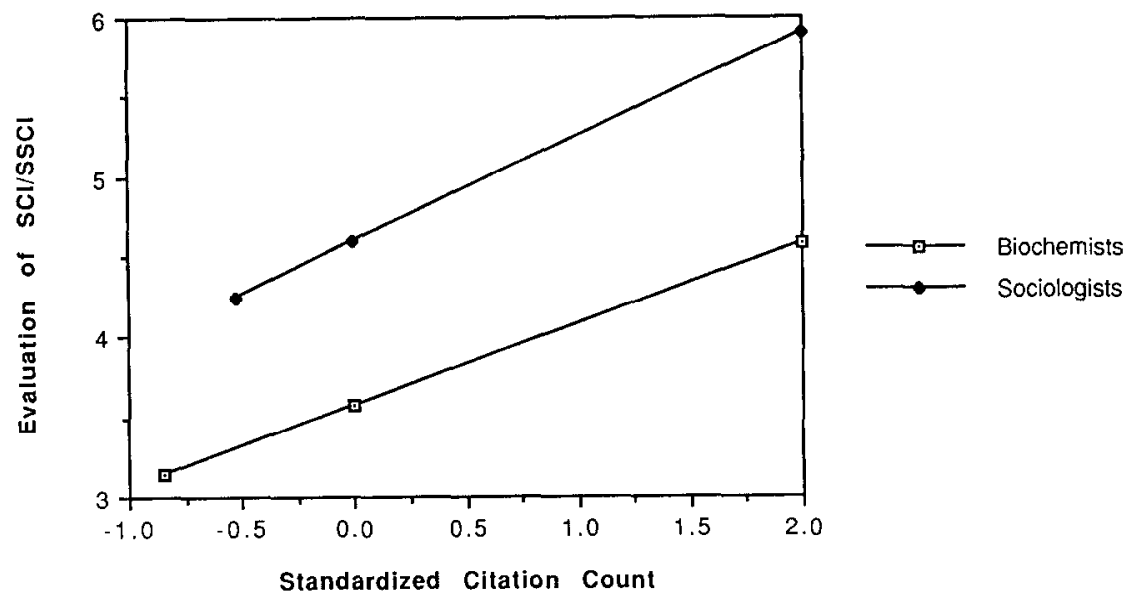

Fig. 2. Relation between Citation to One's Own Work and Evaluations of Citation Indexes, by Field.

are less likely both to have counted individuals' citations, and to evaluate citation indexes as good sources of information about scholarly contributions, than respondents who have received the same number of citations but who are located in departments whose members are cited less often. Since our measures of individuals' citations and average departmental citations are substantially positively correlated $(r=.54)$, each of these variables exerts a "suppressor effect" on the bivariate relation between the other and the two dependent variables. One possible interpretation of this contextual effect is that it reflects a "frog pond" effect (Davis, 1966; Firebaugh, 1980) wherein low-cited respondents in highlycited departments tend to be more negative toward citation counts because such counts suggest that they are relatively weak members of their own departments. If this mechanism is operating, we would expect more highly-cited faculty in departments whose members tend to be cited less frequently to be positive toward citation counts because the counts will confirm that they are doing well relative to departmental colleagues. Another possibility, however, is that regardless of their own citations, scholars in departments whose members tend to be highly cited tend to disparage citation counts because they believe them to be a poor measure of true scholarly contributions. Just as the wealthy disparage pecuniary wealth as only an imperfect signal of more important personal qualities (Veblen, 1899), members of highly cited departments may deny that simple citation counts accurately reflect their superior scholarship. Whatever the exact mechanisms that produce the negative effect of departmental citation levels on use and evaluation of citation counts, it is noteworthy that they work in opposition to the tendency for highly cited 
scholars to think well of such counts because such scholars tend to be found in highly cited departments.

Table 3 also shows that, as hypothesized, sociologists who are quantitatively oriented are more likely than those who are qualitatively oriented to have counted individuals' citations and to positively evaluate citation counts for measuring scholarly contributions. We did not predict the finding in Table 3 that women are significantly less favorable toward using citations to evaluate scholarly contributions than men. In part, this difference may be due to a tendency for women to emphasize the desirability of egalitarian rather than hierarchical social patterns (Chodorow, 1974), or for women to be more likely than their male colleagues to attribute career outcomes to uncontrollable causes rather than to personally controllable ones (Wiley, Crittenden, and Birg, 1979). Indeed, in some circumstances citation counts are not a sex-neutral measure of scholarly merit (Ferber, 1986).

\section{CONCLUSIONS}

Over the last two decades academics have increasingly used citation counts to measure the contributions of individual scholars. Indeed, our survey data suggest that a substantial proportion of biochemistry departments, and a majority of sociology departments, have used such information in hiring, promotion, and salary decisions. Our study investigated several possible sources of variation in individual's use and evaluation of citation counts as measures of scholarly contributions. We developed three hypotheses about such variation from social comparison theory. Of the six tests of these hypotheses, only one-that for hypothesis $2 \mathrm{~b}$ using respondents' evaluations of citation counts—did not yield results consistent with the theory.

Of course, any one of our tests taken in isolation from the others, and from other results we present, is subject to possible alternative explanations. For example, one might argue that the results supporting hypothesis $2 \mathrm{a}$ stem not from a difference in consensus as we postulate but from other differences between sociologists and biochemists. One possibility might be that sociologists are more likely to count citations because they know this is a common practice among their colleagues who study social stratification in science. Data in Table 2 show that biochemists are as familiar with citation indexes as sociologists, however, and that members of the two fields are equally likely to have consulted them for bibliographic purposes. In addition, the greater likelihood that sociology departments have used citation counts in personnel decisions suggests that more than familiarity is involved. Thus, we believe that our results generally support the hypotheses we developed from social comparison theory. 
We advanced one other hypothesis: that sociologists whose style of work is qualitative, holistic, or theoretical would more often oppose using citations to evaluate scholarly contributions than those accustomed to using quantitative data in their own research. We tested this hypothesis by classifying sociologists in terms of their areas of specialization, and found that the results for both dependent variables supported it.

Thus, our analysis suggests that academics' ambivalence about citation counts as a measure of scholarly contributions stems from the interaction of individual and structural factors. Citation counts may appear to affirm or deny scholars' beliefs that their published work is valuable, and their reactions to citation counts tend to protect these beliefs. But use and evaluation of citation counts also varies by the level of consensus in a scholar's discipline, specialties' orientations about the value of empirical data, and the prestige of one's department. These and other sources of ambivalence toward citation counts are likely to continue to fuel controversy over their use as measures of scholarly contributions.

\section{APPENDIX}

\section{The Survey Questionnaire}

1. Are you at all familiar with the Science Citation Index (Social Science Citation Index), which lists individuals alphabctically and shows the citations to each of their publications during a given year?

$$
\text { - 1. Yes }
$$

2. No, never heard of it (please return post card)

2. Have you ever consulted the Science Citation Index (Social Science Citation Index)?

$$
\text { - 1. Yes }
$$

For what purpose? (Check all that apply)

- 1. To use citations to an earlier work to locate more recent work on that topic.

- 2. To determine how frequently particular individuals have been cited during a certain period.

- 3. Other (please specify)

3. Has your department ever made use of citation counts in making decisions about hiring, promotion or salaries?

4. Overall, how useful do you think a citation count is in evaluating 
the contributions of someone in your field? (check one point on the line)

$\begin{array}{lllllllllll}\begin{array}{l}\text { Not } \\ \text { useful }\end{array} & & & & & & & & & \text { Extremely } \\ \text { at all } & 1 & 2 & 3 & 4 & 5 & 6 & 7 & 8 & 9 & 10\end{array}$

\section{REFERENCES}

Alwin, D. F. (1976). "Assessing school effects: Some identities," Sociology of Education 49, 294-303.

Biglan, A. E. (1973). "The characteristics of subject matter in different academic areas," Journal of Applied Psychology 57, 195-203.

Braxton, I. M., and Bayer, A. E. (1986). "Assessing faculty scholarly performance." in Measuring Faculty Research Performance (J. W. Creswell. Ed.), pp. 25-42. JosseyBass, San Francico.

Chodorow, N. (1974). "Family structure and feminine personality," in Women, Culture and Society (M. Rosaldo and L. Lamphere, Eds.), pp. 43-66. Stanford Univ. Press, Stanford, CA.

Cohen, J. (1968). "Multiple regression as a general data-analytic system," Psychological Bulletin 70, 426-443.

Cole, J. R., and Cole, S. (1973). Social Stratification in Science. Univ. of Chicago Press, Chicago, IL.

Cole, J. R. and Cole, S. (1981). Peer Review in the National Science Foundation: Phase Two of a Study. National Academy Press, Washington, DC.

Davis, J. A. (1966). "The campus as a frog pond: An application of the theory of relative deprivation to career decisions of college men," American Journal of Sociology 72, $17-31$.

Ferber, M. A. (1986). "Citations: Are they an objective measure of work of men and women?" Signs 11, 381-389.

Festinger, L. (1954). "A theory of social comparison processes," Human Relations 7, 117 140.

Firebaugh, G. (1980). "Groups as contexts and frog ponds," New Directions in the Methodology of the Social and Behavioral Sciences 6, 43-52.

Garfield, E. (1979). Citation Indexing-Its Theory and Application in Science, Technology and Humanities. Wiley, New York.

Goethals, G. R., and Darley, J. M. (1977). "Social comparison theory: an attributional approach," in Social Comparison Processes (J. M. Suls and R. L. MIller, Eds.), pp. 259-278. Wiley, New York.

Hagstrom, W. O. (1965). The Scientific Community. Basic Books, New York.

Hanushek, E. A., and Jackson, J. E. (1977). Statistical Methods for Social Scientists. Academic Press, New York.

Hargens, I.. L. (1975). Patterns of Scientific Research: A Comparative Analysis of Research in Three Scientific Fields. American Sociological Assoc., Washington. DC.

Hargens, L. L. (1976). "A note on standardized coefficients as structural parameters," Sociological Methods and Research 5, 247-256.

Hargens, L. L., and Hagstrom, W. O. (1982). "Scientific consensus and status attainment patterns," Sociology of Education 55, 183-196.

Jones, L. V., Lindsey, G., and Coggeshall, P. E. (1982). An Assessment of ResearchDoctorate Programs in the United States. National Academy Press, Washington, DC. 
I ewis, I.. S. (1975). Scaling the Ivory Tower: Merit and Its Limits in Academic Careers. Johns Hopkins Univ. Press, Baltimore, MD.

Lodahl, J. B., and Gordon, G. (1972). "The structure of scientific fields and the functioning of university graduate departments," American Sociological Review 37, 57-72.

Long, J. S. (1978). "Productivity and academic position in the scientific career," American Sociological Review 43, 889-908.

Pfeffer, J., Leong, A., and Strehl, K. (1977). "Paradigm development and particularism: Journal publication in three scientific disciplines," Social Forces 55, 938-951.

Rubin, L. C. (1975). "The Dynamics of Tenure in Two Academic Disciplines," Unpublished Ph.D. dissertation. SUNY at Stony Brook.

Smart, J. C., and Elton, C. F. (1982). "Validation of the Biglan model," Research in Iligher Education 17, 213-229.

Stigler, G. J. (1984). The Intellectual and the Marketplace, 2nd ed. Harvard Univ. Press, Cambridge, MA.

Veblen, T. (1899). The Theory of the Leisure Class. Macmillan, New York.

Wade, N. (1975). "Citation analysis: A new tool for science administrators," Science 188, $429-432$.

Whitley, R. (1984). The Intellectual and Social Organization of the Sciences. Oxford Univ. Press., Oxford, UK.

Wiley, M. G., Crittenden, K. S., and Birg, L. D. (1979). "Why a rejection? Causal attribution of a career outcome event." Social Psychology Quarterly 42, 214-222.

Yoels, W. C. (1974). "The structure of scientific fields and the allocation of editorships on scientific journals: Some observations on the politics of knowledge." Sociological Quarterly 15, 264-276.

Zuckerman, H., and Merton, R. K. (1972). "Age, aging and age structure in science," in Aging and Society (M. W. Riley et al., Eds.). Russell Sage, New York. 